\title{
JURISPRUDENCIA AMBIENTAL EN LA COMUNIDAD DE MADRID (PRIMER SEMESTRE 2021)
}

\author{
Daniel B. Entrena Ruiz \\ Profesor Contratado Doctor \\ Universidad Carlos III de Madrid \\ daniel.entrena@uc3m.es ${ }^{1}$
}

SUMARIO: 1. Sentencias del Tribunal Superior de Justicia de Madrid, no 185/6021, de 6 de marzo de 2021 (Número Recursos: 277/2021 y 278/2021, Ecli: ES:TSJM:2021:5, Ecli: ES:TSJM:2021:6). Derechos de reunión y manifestación. Limitación por COVID-19. Principio de precaución ambiental. 2.- Sentencia del TSJ de Madrid no 29/2021, de 29 de enero de 2021 (Número Recurso: 1056/2018. Anulación de Zona de Bajas Emisiones Madrid Central

\section{Sentencias del Tribunal Superior de Justicia de Madrid, $n=185 / 6021$, de 6 de marzo de 2021 (Número Recursos: 277/2021 y 278/2021, Ecli: ES:TSJM:2021:5, Ecli: ES:TSJM:2021:6). Derechos de reunión y manifestación. Limitación por COVID-19. Principio de precaución ambiental}

Las resoluciones referenciadas examinan la conformidad a Derecho de la prohibición de reunirse el día 8 de marzo par celebrar el Día Internacional de la Mujer, que la Delegación del Gobierno de Madrid había decidido, por razones sanitarias, esto es, para evitar la propagación del COVID-19.

Los organizadores de las reuniones manifestaban en su comunicación a la Delegación del Gobierno que garantizaban el cumplimiento de las medidas sanitarias, en particular respecto la obligación de llevar mascarilla protectora, el

\footnotetext{
${ }^{1}$ Open Researcher and Contributor ID (ORCID): 0000-0003-1393-0736 
respeto de la distancia de 1,5 metros de seguridad entre las personas reunidas y la no formación de grupos.

Frente a los derechos de reunión y manifestación, la Delegación del Gobierno argumentaba la necesidad de proteger los derechos a la salud y, por ello, a la integridad física y moral y el derecho a la vida, con los que entrarían aquellos primeros en conflicto, estableciendo el Real Decreto 926/2020, de 25 de octubre, I posibilidad de limitarlos cuando no se garantizase la distancia de seguridad.

Pues bien, la razón de traer a estas páginas las resoluciones judiciales es difundir el sentido que está cobrando el principio ambiental de precaución en el actual escenario pandémico, pues de servir para limitar actividades económicas privadas cuando se desconozcan los efectos que sobre el medio ambiente puedan generar, ha pasado a servir como justificación de la restricción de derechos fundamentales cuando, no obstante, se pueda encontrar en peligro la salud pública.

Una doctrina que ha venido sirviendo para justificar por algunos Tribunales Superiores de Justicia los llamados cierres perimetrales, argumentando que las características del COVID-19 impiden conocer su capacidad concreta de contagio $y$, por tanto, que se pueda abordar dicha medida sin discriminar entre personas o grupos de personas, como indica la normativa sanitaria que se efectúe, justificando así su aplicación colectiva sobre ámbitos territoriales.

Ahora dicho principio ha servido, además, para limitar la restricción de los derechos fundamentales de reunión y manifestación (Sentencias del TSJ de Madrid, Sala de lo Contencioso Administrativo de 30 de abril de 2020, 4 y 11 de febrero de 2021, y ahora ya la que comentamos).

Entre los problemas que plantean estas resoluciones se encuentra la cuestionable aplicación del principio de proporcionalidad que efectúan -que más bien brilla por su ausencia- pues sin perjuicio de la innegable justificación de la restricción efectuada, sobre la base de la legitimidad del fin de interés general perseguido, y más a la vista de la situación epidemiológica en cada concreto momento -número 
de contagiados y cepas del virus-, se aduce además la imposibilidad de prestar el servicio policial con suficiente cobertura ante la proliferación de concentraciones, pero sobre todo no se evalúa la necesidad de las medidas adoptadas, esto es, la existencia de otras menos lesivas para los bienes jurídicos afectados, por ejemplo, acotar el número de personas concentradas.

Dicho criterio ha sido confirmado incluso por el propio Tribunal Constitucional cuyo Auto de 30 de abril de 2020 (Rec. 2056/2020) es citado en extenso por las Sentencias que comentamos, del cual extraemos el siguiente párrafo, altamente significativo de lo que indicamos:

"En todo caso, parece obvio que la prohibición de celebrar la manifestación, que se deriva claramente de la resolución judicial impugnada, guarda una relación lógica y de necesidad evidente con la finalidad perseguida por esa misma interdicción: evitar la propagación de una enfermedad grave, cuyo contagio masivo puede llevar al colapso de los servicios públicos de asistencia sanitaria. La adecuación entre la finalidad pretendida por la limitación y la herramienta jurídica empleada en este caso, no parece por tanto inexistente. $Y$ no se trata aquí de garantizar del orden público o de asegurar la no alteración del orden público. Tampoco la declaración del estado de alarma se ha basado en la preservación del orden público, sino en la garantía del derecho a la integridad física y la salud de las personas. Por eso nos encontramos en un escenario en que los límites al ejercicio de los derechos, que indudablemente se dan, se imponen por la necesidad de evitar que un ejercicio extralimitado del derecho pueda entrar en colisión con otros valores constitucionales ( STC 42/2000, de 14 de febrero, FJ 2). En este caso los valores de la vida, la salud y la defensa de un sistema de asistencia sanitaria cuyos limitados recursos es necesario garantizar adecuadamente".

Se opta así, a nuestro modo de ver, por un juicio maximalista y poco matizado de la restricción de derechos fundamentales, que casa mal con la tradicional interpretación estricta que este tipo de medidas suelen tener, conforme al principio favor libertatis, como se expone en la cuantiosa jurisprudencia constitucional que 
la propia Sentencia comentada relata (entre otras muchas, STC 301/2006, de 23 de octubre, STC 66/1995, de 8 de mayo).

En particular, pese a que el Tribunal en las Sentencias que referenciamos, dice examinar la proporcionalidad de la prohibición, mencionando los tres escalones que ese juicio requiere, se limita a evaluar la plenitud de las medidas propuestas en la comunicación a la Delegación del Gobierno para evitar la propagación, pero nunca llega a plantearse si en lugar de la prohibición eran admisibles otras medidas menos lesivas: "En particular, no se ofrecen medidas de seguridad, concretas e idóneas, para garantizar qué durante la concentración y la deambulación de los participantes en la manifestación, se mantenga la distancia social mínimamente necesaria o para evitar que algunas personas lleguen a retirarse la mascarilla para apoyar en voz alta los objetivos de la manifestación. $Y$ tampoco se ofrecen, o se indica, las concretas medidas de seguridad que se van a adoptar para comprobar que las personas que acudan a la convocatoria aporten no solamente mascarillas sino que éstas mascarillas sean homologadas, como se hace constar en la comunicación, y que guarden las necesarias medidas de seguridad interpersonal. La imprecisión de las medidas de seguridad previstas para garantizar la salud pública, especialmente relevantes en el escenario de gravísima pandemia en que nos encontramos, no permite conjurar el alto riesgo de que el desarrollo de una concentración, como la comunicada por el promotor, favorezca la propagación de coronavirus tanto entre los manifestantes como posteriormente a sus familiares y su círculo social, e incluso, a otras personas ajenas al acto o concentración".

En consecuencia, la Sala no hace sino aplicar el principio de precaución para impedir el ejercicio de un derecho fundamental, y juzgar insuficiente las condiciones para permitirlo, en lugar de proyectar el juicio sobre la legalidad de la actuación administrativa cuestionada como expresamente reconoce en su Fundamento Jurídico Sexto:

"Finalmente, hemos de traer a colación el principio de precaución o cautela que tiene su origen en las normas europeas de protección del medioambiente y que 
después se fueron extendiendo a otros sectores como el de la protección de la salud. Se trata de un principio aplicable en todos los casos en los que existan indicios de un potencial un riesgo grave, para el medio ambiente o la salud de las personas. Para su aplicación, no es necesario que la Comunidad científica hay verificado que se trata de un riesgo real y su alcance. La mera verificación de indicios fundados de riesgo grave, obliga a los poderes públicos a tomar las medidas de protección necesarias, para eliminar o disminuir el riesgo, como si ya hubiese sido confirmado el riesgo (...).

El principio de precaución fue incorporado a nuestra legislación sanitaria, en la Ley 33/2011, de 4 de octubre, General de Salud Pública (LGSP). Concretamente en los artículos 3 y 27 se reproducen, casi literalmente, las interpretaciones de las instituciones europeas. Tanto es así que el tenor literal del artículo 3.4 dice: "Principio de precaución. La existencia de indicios fundados de una posible afectación grave de la salud de la población, aun cuando hubiera incertidumbre científica sobre el carácter del riesgo, determinará la cesación, prohibición o limitación de la actividad sobre la que concurran". Mientras el citado artículo 27, dispone que una vez de da el supuesto de hecho de aplicación del principio de precaución, el Estado está obligado a proteger la salud de la población mediante actividades, servicios y medidas que eliminen o disminuyan los riesgos".

\section{2.- Sentencia del TSJ de Madrid no 29/2021, de 29 de enero de 2021 (Número Recurso: 1056/2018. Anulación de Zona de Bajas Emisiones Madrid Central}

La Zona de Bajas Emisiones (ZBE) Madrid Central ha suscitado una litigiosidad tremenda, tanto respecto a su aprobación y regulación mediante la Ordenanza de Movilidad Sostenible (OMS), como respecto a las medidas adoptadas por el equipo de gobierno municipal, de los Grupos políticos municipales del Partido Popular y Ciudadanos, que intentaron suspenderla nada más tomar posesión.

Respecto a estos intentos de suspensión, ya se dio cuenta de ellos y de su infructuoso resultado, en los compendios del segundo semestre de 2019 y 2020 de esta Revista. 
Así, en el compendio jurisprudencial de 2019 se referenciaban los Autos de los Juzgados de lo Contencioso-Administrativo (JCA) de Madrid $n^{\circ} 24$, de 5 julio de 2019, y o 7 de 16 de julio de 2019, que ordenaron la suspensión cautelar del Acuerdo de la Junta de Gobierno Local del Ayuntamiento de Madrid que a su vez suspendió la Zona de Bajas Emisiones (ZBE) de esta ciudad, mediante la suspensión del régimen sancionador.

Posteriormente, en la crónica jurisprudencial del segundo semestre de 2020 informábamos de las Sentencias del Juzgado de lo Contencioso-Administrativo no 7 de Madrid, de 17 de junio de junio de 2020 (PO no 302/2019) y del Juzgado de lo Contencioso-Administrativo o 24 de Madrid de igual fecha (PO 298/2019), que declararon no ajustada a Derecha la mencionada suspensión del régimen sancionador, por motivos distintos pero igualmente válidos: en un caso no ajustarse a los motivos de suspensión del régimen de ZBE previstos en la OMS, y en otro caso por afectar la suspensión de esta zona al principio de regresión ambiental.

Por lo que respecta a la propia OMS, en ese mismo número del Repertorio, referenciábamos las Sentencias del Tribunal Superior de Justicia de Madrid de 27 de julio de 2020 (no rec. 902, 911, 988/2018), que estimaron los recursos interpuestos contra dicha norma por contencioso-administrativos interpuestos por la Comunidad de Madrid, la empresa DVuelta Asistencia Legal, y varios concejales integrados en el Grupo Municipal Popular.

La estimación de los recursos obedeció a que la OMS no fue sometida a un nuevo trámite de información pública tras introducirse algunas modificaciones precisamente respecto las ZBE- que lo aconsejaban y que no iba a acompañada de memoria económica previamente a su aprobación.

La Sentencia que ahora referenciamos del TSJ de Madrid resuelve el recurso presentado contra la OMS por una entidad privada sustentado, en lo esencial: i) en la ausencia de memoria económica; ii) en la afección por la norma de derechos susceptibles de amparo constitucional (destacadamente el de libertad 
deambulatoria); iii) nuevamente, en la ausencia de trámite de información pública en relación con las modificaciones introducidas en la OMS, por ser sustanciales, tanto en lo relativo a Madrid Central como la denominada Colonia Marconi, localizada en un polígono industrial de Villaverde, en el que existe abundante prostitución.

Este hecho motivaba, para el Ayuntamiento de Madrid, la posibilidad de restringir por razones de protección de la seguridad pública y vial, la circulación por dicha zona. Sin embargo, la resolución judicial entiende que se trata de una medida insuficientemente motivada.

Esta cuestión, y la contravención de la Ley de Capitalidad y Régimen Especial de Madrid, en lo relativo a su excepción por la OMS de la incorporación de imágenes de vehículos infractores cuando la denuncia provenga de personal auxiliar de la zona de estacionamiento regulado, que no acepta el Tribunal, conducen al "remate" de la referida norma municipal, y la consiguiente necesidad de una nueva que en estos momentos se está tramitando. 